\title{
University of New South Wales
}

\section{Deborah Bird Rose}

\section{Slowly writing into the Anthropocene}

\section{Abstract:}

This paper argues against abstracts.

Biographical note:

Deborah Bird Rose is Professor in the Environmental Humanities Program at the University in New South Wales. Her research focuses on multispecies communities in this time of extinctions. She is a Fellow of the Academy of Social Sciences in Australia, and a founding co-editor of the new journal Environmental Humanities. Recent books include Wild Dog Dreaming: Love and Extinction (2011, University of Virginia Press), the re-released second edition of Country of the Heart: An Indigenous Australian Homeland(2011), and the third edition of the prize-winning ethnography Dingo Makes Us Human (2009).

\section{Keywords:}

Creative writing - Ecology - Slow-writing - Fragmentation - University-zombies Multispecies-ethics - Anthropocene 


\begin{abstract}
You have found a way to write about me using only words that hold all things up to be gazed at from the outside. Words that belong in travel documents and phone books, in government legislation, flight protocols, codices for the handling of rare plants or service manuals for the elimination of the past. This is how it has to be, I understand. Narratives of the transforming self have had their day. Intentions and inwardness flicker out like a box of wires and a sputtering headlamp left out in the night rain. It is the brutal age of the limited exhibit - pinned, classified and left to deal with it. The sea has been erased from the crab's memory. For now shells and fossils still speak. Vast creatures have moved through me and scamper into other trees (Boyle 2012: 1).
\end{abstract}

\title{
Gazed at from the outside
}

Late modernity reveals itself in its violent breaching of the defences which those who benefit from it had erected to shield themselves from its effects. We might understand this as reflexive modernity, or as extravagant wastage of lives and of earth, or as postmodernity in the sense of modernity without the hope that served as counterbalance to, and justification for, violence, or indeed in numerous other modes of addressing modernity, post-modernity, and (more recently) the Anthropocene. We should also understand this circling back of violence as the necessary feedback loop in a world of connections, fuelled by a stupendous capacity to ignore this very world within which our lives are sustained. Perceptions of the coupling of social and ecological systems arise in the effects of human action emerging from disengaged and fragmenting forms of knowledge. As development expert Francesca Apffel-Marglin puts it, our system of disconnected knowledge 'has proved dramatically successful at creating material abundance and technological advance, but disastrous at maintaining social and natural ecology'. Central to her argument is the fact that the distribution of abundance is wildly unequal, and that what counts as a technological advance in solving any given 'problem' is often extremely problematic, if not outright dangerous, destructive, unpredictable, and generative of much larger problems in the longer term.

Unmaking is going on all around us these days. It is not only over there in other places, other lives, other communities; it is here amongst us, fragmenting our jobs, our lives, our communities. We are participants both in unmaking and in being unmade. Of the many strands of the complex and disastrously cascading effects of late modernity, I focus on one: the interrelated qualities of the great unmaking of ecological, social and intellectual systems. I am concerned to diagnose the ethical paralysis that is invading our lives, and to propose slow writing as one response to our impossible position as participants in and witnesses to catastrophes beyond our comprehension.

But let us first consider the process of unmaking as it has been discerned in contestations over a mountain that has not yet been unmade. Recall that Aldo Leopold once suggested that it takes a mountain to 'think' the long term connectivities that enable wolves and deer and grass all to flourish. His invitation to 'think like a mountain' beckoned us toward an encounter within which to find dynamic proximities of ecological mutualisms involving both life and death. The process of unmaking works against this form of connected 'thinking like'. Its vision is darker and depends 
on thinking discontinuity, thinking fragmentation; thinking replaceable, interchangeable, isolated; thinking 'deal with it'.

The perspicacious analysis made twenty years ago by Alf Hornborg shows this thinking in action: if it takes a mountain to think long-term connectivity, it takes modernity to think of a mountain as a gravel pit, and to haul it away piece by broken piece. His study addresses confrontations over the future of a sacred mountain: was it to continue to exist in its dynamic, ever-changing connectivities, or was it to be broken down into isolated units and dispersed? In his article 'Environmentalism, ethnicity and sacred places: Reflections on modernity, discourse and power', Hornborg describes the political battle to save Kelly's Mountain, known to Mi'kmaq people as Kluscap. His wider analysis investigates the workings of modernity. He writes that 'turning a mountain into gravel is facilitated first by breaking it down conceptually' (251). Separation, fragmentation, the breaking down of connectivities into bits and pieces: this is the 'decontextualising cosmology' (263) known as modernity. It is implemented through scientific and technological methods of manipulation and control. It is extremely powerful, and many of us benefit from it enormously in the short term.

Hornborg writes that modernity disembeds that which is embedded, aiming to decontextualise, and to transcend and encompass the local. This work of encompassing replaces living systems with disarticulated fragments, places experience far from us rather than close to us, and becomes part of the process of dulling the ethical imagination, thus contributing to subjectivities that both ethically and cognitively are far from experience (258). Leopold's mountain, the one with which he invited us to think, is a place where living beings flourish together; it is a place of give and take, of flows and mutualities, of births and deaths. Mutualism invites us to think relationally, and thus to become attentive to the lives of a myriad selfhoods. In the midst of all this relationality, our ethical imaginations are called upon. To think with Leopold, and with a mountain, is to be entangled within life rather than gazing upon it as if from some putative 'outside'.

I have drawn on the case study of the mountain because it offers such a clear example, and because my concerns inevitably gravitate toward the effects of human actions on the nonhuman world, but my purpose is not exactly to show that unmaking is all around us. For the most part, surely, we already know this. Rather, I want to proceed to the wider question of what a scholarly writer might do in the face of all this anthropogenic disaster. I first indicate several contexts of unmaking in order to be clear that we who ask these questions about writing are situated within the unmaking, both as contributors to it, as objects of its process, and as persons with a voice with which to offer antidotes to these poisons of our time.

The process that is so clear and so alarming in the dismantling of a mountain may be both closer and more uncomfortable when it takes place within our communities. If the first step in unmaking is fragmentation by discursive means, the unmaking of our communities may fairly be said to have been signalled by Prime Minister Margaret Thatcher in her infamous statement that 'there is no such thing as society'. This great verbal warhead laid out a conceptual 'bare earth' in which social bonds, networks, 
solidarities, responsibilities, and conflicts (in so far as they were founded in group interests and action) were declared not to exist. The results of decades of unmaking surround today and have become the subject of a huge analytic and critical literature. A particularly insightful engagement with these issues was offered by Tony Judt in his book Ill Fares the Land. The introduction, delightfully titled 'A guide for the perplexed', opens with words that resonate deeply: 'Something is profoundly wrong with the way we live today. For thirty years we have made a virtue out of the pursuit of material self-interest: indeed, this very pursuit now constitutes whatever remains of our sense of collective purpose. We know what things cost but have no idea what they are worth'. He points out that much of what we now take for granted dates from the $1980 \mathrm{~s}$; from the time, that is, when social bonds were being fractured, and material self-interest was taken to be the single most significant driver of human life. Judt's diagrams show scurrilously rapid increases in income inequality, and correlate levels of inequality with pathological social problems. He asserts that 'there is a reason why infant mortality, life expectancy, criminality, the prison population, mental illness, unemployment, obesity, malnutrition, teenage pregnancy, illegal drug use, economic insecurity, personal indebtedness, and anxiety are so much more marked in the US and the UK than they are in continental Europe' (18). That reason, according to Judt, is the corrosive effects of inequality on society (21).

The situation may be even more dire, according to sociologist Michael Pusey. The unmaking proceeding under the label of 'economy' is not just corrosive, but amounts to an assault on civil society. He shows that fragmentation works to unmake our social relations, and thus that economic decision-making, represented as a matter of free choice based on putative self-interest, neutralises ethics. Furthermore, he writes that 'the raw material for economic development... is really civil society itself'. This is to say that 'development' consumes civil society.

To my mind, one of the most pervasively deceitful of the great lies of this era is that of the level playing field. Out on the so-called level playing field, the unmaking is deemed already to have occurred, leaving a ground fractured into isolated, interchangeable, comparable units. This imaginary setting purports to offer perfect competition and perfect choice, such that the participants themselves are interchangeable and substitutable because they have no history, no culture, no familial or community ties, and no commitments (other than to themselves as agents of material self-interest). Part of the deceitfulness lies in the demonstrable fact that when it comes to inequality, people's histories and cultures do matter. Intergenerational social mobility in the USA is decreasing, not increasing (Judt 2010: 16), and that fact is demonstrated in Australia as well. But along with masking the social causes of inequalities, the level playing field neutralises ethics. It is, in effect, a human gravel pit - a ground of fragments within which there are no actual selves in relationships with others, but only isolated units among whom no ethics may be possible. In short, unmaking cuts across the relationships which give rise to ethics, leaving wounded remnants whose purposes and meanings are being erased. In Boyle's words, living selves 'flicker out like a box of wires and a sputtering headlamp left out in the night rain' (2012: 1). 
Thinking 'like a mountain about to be broken down into gravel' shows us that this same unmaking is working upon universities, and thus upon the lives of scholars and writers. My life's work thus far has been in academic scholarship and its practical applications in the service of justice, and I am acutely aware of how unmaking arrives under the banner of excellence. Fragmentation is accomplished as our work is broken down into measurable units, the units are aggregated into arbitrary categories, and the categories compared. We are urged with both carrot and stick to set higher targets, engage in more fragmentation in order to produce more and more units. There is never a point at which enough is enough. It has long been known in the academic world that fragmentation signals destruction. As Gregory Bateson wrote to the Regents of the California University system back in the 1970s, 'Break the pattern which connects the items of learning and you necessarily destroy all quality'.

We observe this destruction, and we experience it. In Suzanne Ryan's powerful words, the culture of audit and surveillance is transforming us into zombies. Under the label of quality our scholarship is fragmented into a gravel pit of publication categories, numerically defined fields of research, rankings, citation indexes and other outputs. Our PhD students become completion rates, our supervision is measured by boxes ticked online, our deans get bonuses for flogging us to improve our numbers, and the achievement of targets nudges aside, and may ultimately replace, the factors that go into real scholarship, including: thought, learning, creativity, depth of perception, and intersubjective dialogue. As individuals we are 'pinned, classified and left to deal with it' (Boyle 2012: 1). And so of course many of us feel torn to pieces by the gap between the complex human creatures we know ourselves to be and the coerced caricatures that purport to represent us.

\section{Antidotes}

How awful it is that the big forces of power and authority that drive the assault on the earth, civil society, universities and ourselves seem so unstoppable. Isabelle Stengers uses the term 'spiritual capture' to gesture toward the sense of powerlessness that overtakes us all too often as we consider our world, our lack of capacity to change things we know need changing, and, it seems to me, our dismay at our complicity in so many assaults.

Stengers talks of sorcery, suggesting that we are under a spell; she calls, therefore, not for revolution, but for antidotes. One antidote she offers is, actually, this living world, the world we are rapidly wrecking. In her beautiful essay on peace, she argues for a cosmopolitics which 'defines peace as an ecological production of actual togetherness'. Not unity, she emphasises, but connection. Peace entails a commitment to the reality of the world, a commitment to being 'for the world'. This is an extremely open-ended project, and one has no idea where it will lead. Connections are non-linear, and there is no single method for approaching commitment. Truly, if we are to remain embedded within our shared, or partially shared, life worlds, we cannot develop prescriptions that hold true across contexts, i.e., we cannot decontextualise or disembed. We will be working out methods and strategies for achieving the committed life within our contexts and amongst those who are near to us. 
Antidotes require slow work, not only in the sense of taking time, slowing down, and doing things carefully, but also in the sense of living in the present temporalities, localities, and relationalities of our actual lives. The method and ethic of slow is well developed in relation to food and other contexts of daily life. Slow food, for example, is based on local products, is often organic and seasonal, and is often marketed through producer-consumer alliances that develop ethical relationships between producers and consumers. Slow is a movement toward quality over quantity, toward connection rather than fragmentation, and toward ethical mutualities rather than selfinterest alone. In relation to scholarship, slow is a movement toward thought and attention, expressed particularly engagingly by The Slow Science Academy whose motto is 'Bear with us, while we think' (2010).

\section{Slow ethics}

I have briefly indicated that the great unmaking entails a loss of possibilities for an ethical life because fragmentation, when it does not actually cause death, causes such separation and isolation that the ground for ethics appears to be broken. Modes of commitment that work as antidotes necessitate that our ethics be particularly attuned to our late modern condition. In this light, we will be extremely wary of seeking to work against fragmentation by espousing unity. In the words of John Roth: 'Any ethical system that thinks it has the solution to every problem has the potential to be genocidal. Ethics must no longer be a closed system, but a way of living ... in openness to the vulnerability of others'. Living beings call and respond; ethics are situated in bodies, in time, in place and, necessarily, in encounter.

I will take up issues of embodied and emplaced ethics in greater detail, but first I want to be sure that neither bodies nor places are thought to be ethically unique to humans. My research with Aboriginal people in Australia has strengthened and deepened my understanding that life emerges from dialogue amongst persons; it depends on relationality, interdependence, and mutual flourishing. In this context, persons are mindful beings. And in contrast to western binaries that would put humans on one side of a boundary where mind and culture are pervasive, and put everything nonhuman on the other side of that boundary, asserting that there is no mind or culture over there, Australian Aboriginal people, like Indigenous people in many parts of the world, understand the world they live in to be saturated with mindfulness. Graham Harvey has recently brought fresh insight to the term animism, summarising and extending the work of several key thinkers who are rehabilitating the term from the old anthropological evolutionary view that animism was a primitive and erroneous form of understanding the world. The new work on animism shows a subtle and generally observationally astute view of nonhuman sentience. Harvey's definition is succinct and appropriate: animism involves the recognition 'that the world is full of persons, only some of whom are human, and that life is always lived in relationship to others'. According to my Aboriginal teachers, plants as well as animals are sentient, and the earth itself has culture and power within it. In this mode of thought, we are all culture-creatures, we are intelligent, we act with purpose, we communicate and take 
notice, we participate in a world of multiple purposes. It is a multi-cultural world from inside the earth right on through.

Similar understandings have been developed by non-Indigenous scholars such as, for example, the philosopher Val Plumwood who argued for a philosophical animism within which it would be possible to recognise the kinship of life on earth. Kinship, she was arguing, underlies human capacity to recognise 'earth others as fellow agents and narrative subjects', a recognition that 'is crucial for all ethical, collaborative, communicative and mutualistic projects, as well as for place sensitivity'. Ethics emerging from emplaced, embodied encounters among persons constitute a moral compass in life-words that are always becoming (always emergent). I want to be clear that encounter, in any fundamental sense of the term, does not preclude conflict; what we, or anyone, make of conflict is another matter, but I am not suggesting that there can be life (human or nonhuman) without conflict. The more important point is that an ethics of mutual becoming starts with a presupposition of relationality and potential mutuality, not a presupposition of isolation and inevitable hostility.

The argument is that one's own self is always entangled with all the others who precede it and who make life possible, moment by moment. In responding to others both self and other continue those entanglements. The self includes one's capacity for moral knowledge and action: 'I become a moral agent and not a power instrument, when I understand that my existence is entangled with other lives and is, therefore, responsible'. This very human statement of ethical selfhood is probably not characteristic of all nonhumans, although recent work on the moral lives of animals demonstrates that moral sensibility is part of our evolutionary heritage as social animals. But my analysis does not depend on the moral lives of other animals. I am concerned quite specifically with the species that is generating vast wreckage upon the lives of others. I am focussed on the responsibilities of humans.

Positioned ethically in a world of becoming, which is to say in attention to others and to responsibilities, one must necessarily be both situated and available to the call of others. Another term for this situated availability is dialogue. As I have written elsewhere, the term dialogue is widely and frequently misused, covering over monologue with a pretence of give and take. Like the term 'consultation', it is often encountered as a box to be ticked rather than a process through which to work toward an as-yet undetermined outcome. And yet dialogue is, I believe, a necessary concept for the slow work of ethics and witness. Dialogue is a form of ethical practice amongst subjects (human and nonhuman). The philosopher Emil Fackenheim draws on the work of Rosenzweig to articulate two main precepts for structuring the ground for ethical dialogue. The first is that dialogue begins where one is, and thus is always situated; the second is that dialogue is open, and thus that the outcome is not known in advance. Dialogue thus contrasts forcibly with the pseudo-consultations undertaken under the rubric of restructuring. Who among us has not encountered the requirement to participate in consultations about decisions already made, and witnessed phoney tantrums and bullying little hissy-fits? As we are coming to know all too well, these falsely open ordeals are based on the unbearably demeaning requirement that people participate in a charade the outcome of which is fully known in advance, an outcome often quite detrimental to those who are forced to participate. 
The situatedness of dialogue is context-specific. It includes the here and now of encounters in place and time. It includes the history of the place and the personal and social histories of the parties to the encounter. The situatedness of dialogue means that our histories precede us, and that the grounds of encounter are never abstract or empty. There are no level playing fields in dialogue, and thus there can be no faceless participants. There is no place for those who simply do their job in a context such that they bear no responsibility for the effects of their actions. As humans we come into multispecies dialogue bearing the burden of our responsibilities in the cascading damage of modernity that is now carrying us into an era, the Anthropocene, of unmaking.

The concept of openness is equally challenging. Openness is risky because you do not know the outcome in advance. You would have to be clever in your proposal writing if you hoped for funding. To be open is to hold one's self available to others: you take risks and make yourself vulnerable. But this is also a fertile stance: your own ground, indeed your own self, can become destabilised. In open dialogue one holds one's self available to be surprised, to be challenged, and to be changed. This ground of openness is a place where knowledge arises. Unmaking dismantles dialogue, and is undoing possibilities for diversity of knowledge as well as ethics. At the same time, humans are not the only creatures who are gaining knowledge. The question of what others may be learning about humans at this time is indeed terrible to imagine.

\section{Writing and witness}

How are we situated in the face of this great unmaking? Dialogically, what is our place, our history, our genre of being? And what of our actions? What about all this erasure, to echo Boyle's term? Stengers writes of commitment to life, of being 'for life'. My work has taken up this challenge, and seeks commitment 'with' life; I take it as given that there are fidelities within life with which I as a human person am called to keep faith.

The great Native American author Linda Hogan tells us that writing is an offering, a way of giving something to the world (pers. comm. 2010). Writing into the great unmaking is a form of testimony, and it arrives with the necessity and the impossibility of speech. In Stenger's memorable words, 'no one is ready for what's coming. It is beyond all of us'. The impossible position concerns the necessity of speaking of that which is beyond our ken. Our position requires us to acknowledge ethical silence, and our challenge, therefore, is to speak without over-riding that silence. But ethical silence, in James Hatley's terms, does speak: it speaks the quandary of response and responsibility toward that which is beyond our comprehension, 'beyond all of us'. This is our situation now. We are called to intervene, and all too often we find that we are helpless to intervene. Here, now, in the face of all this loss, we are called toward an impossible position. To turn our backs on those who are targeted for destruction, or who are abandoned on a spiral of loss dealing toward greater destruction, is to refuse the ethical call. Inevitably, of course it entails turning our backs on ourselves. To face others is to become a witness, and to experience our incapacity in this position. It requires us, in Hatley's words, to address 
the stories that cannot be told, to write about that which we can never adequately comprehend. It is to remain true to the lives within which ours are entangled, whether or not we can accomplish great change.

I am thinking witness and ethics within a conversation that is open to the world of life. As a writing practice, it may be an antidote to the spiritual capture brought on by so much, and such escalating, loss. To write into unmaking is a performative practice that calls for multiple strategies, in keeping with the fact that we have multiple audiences, multiple strands of analysis, multiple objectives. Initially, as I was trying to reconcile myself to university demands that seemed at odds with my own sense of the significance of my research, I decided to divide my work into fast work and slow work. The two are not wholly separable, but the major difference, in my mind, is that fast work is strategic and slow work is dialogic. Strategically developed work is excellent; we all do it, and in the fast world, there is an important place for it. To try to avoid slipping into zones where my writing could be captured, though, I made a little rule for myself - slow work would be called forth dialogically. As stated, the theory of dialogue articulates a position of situated availability. In a multispecies, multicultural world of life, dialogue is not a single-species project. As knowledge, and as subjectivity, dialogue emerges within 'biosocial loops'. It follows that research founded in and arising from dialogue is not a single-species project. If our work is to keep faith with life, we need Barad's and Haraway's concept of world-making, or worlding, the main point being that as the world is always coming into being, our decisions are part of the world's becoming. Barad famously refers to this agentic quality of life as a performative metaphysics (2003). Her argument is that in this world of emergent life, agency necessarily entails configuring (or reconfiguring) the world (2003: 818). The world emerges from multi-species decisions. Van Dooren states this position extremely effectively: 'we are required to make a stand for some possible worlds and not others, we are required to begin to take responsibilities for the ways in which we help to tie and retie our knotted multispecies worlds'. My approach in waiting for writing to be called forth entails letting the world guide the worldmaking. Slow writing, therefore, is not driven in the first instance, by academic issues. It is not driven at all. It is called forth and my commitment is to keep faith with life by responding as best I can.

Stories are key antidotes in slow writing. The philosopher Glen Mazis draws on the work of Philip Hallie to develop the argument that when ethics arise out of events involving embodied beings and actual encounters, understanding depends on stories. In the slow ethics of encounter, we are not talking about concepts to be written about (as if from the outside), but rather about events to be participated in and shared, imaginatively and otherwise. Stories themselves have the potential to promote understandings of embodied, relational, contingent ethics. My slow writing is called forth by events within the living world, and it seeks to pull readers into ethical proximity with those events. An example is the first paragraph of my book Wild Dog Dreaming. In this paragraph I wanted to tell a (very short) story, and to communicate that I was writing in the face of death, using the term 'face' in a Levinasian sense of that which commands me ethically. I hoped both to invoke and destabilise bodies and places, to generate uncomfortable proximity, and to pose ethical questions. 
A few years ago my friend Jessica stopped by the office to tell me something awful. Not far from Canberra she had seen a tree that was strung up with dead dingoes. Horrified and inexorably curious, I went to see for myself. It was as she had told me: the dingoes were suspended by their hind legs, heads down, bodies extended, another 'strange fruit' in the annals of cruelty. I prowled the edges of the area, my mouth dry and my throat constricting as the smell of decay and the horror reached into me. Vertigo was causing a sense of estrangement, and I could not be sure where I was, so that I kept looking back to the truck to remind myself that this was the $21^{\text {st }}$ century, that I'd driven here from my home in the national capital of Australia, that I was on an ordinary dirt road near the edge of a National Park, that in a few minutes I would get back in the truck and drive away. In some fundamental sense I was lost. Dear God, I thought, where are you?

As I started writing the words called forth in this encounter, I was haunted by dead bodies, living bodies, Dingo families (human and nonhuman), stories, teachings, and the beautiful harmonies that dingoes send out across the night air, and which here had been so suddenly and brutally cut off. I knew that at every point I would want to resist letting this work become predictable. I decided it would be a book rather than just a one-off article, and that each chapter would be called forth by something outside myself. Furthermore, each chapter would include dogs, and each chapter would take up a story, however short it might be. I wanted to keep to the forefront of my thinking, and of the reader's experience, that the trigger for this work was an encounter that demanded response. It was not about theory, or representations, or ontologies; it was about finding one's self face-to-face with all these dead bodies, all these dingoes who had been alive not so long ago, and who had been purposively killed, and purposively put on display.

And even as I thought through how I might do this, I wondered if I was I becoming overly prescriptive. Would it become predictable? Was I trying to place too much control on that which I sincerely wanted to keep open? Was there only one way of writing? And could different ways be worked into one text? It was at this point that I wrote a manifesto for myself. I felt the need to articulate to myself the fidelity to which I was seeking to hold fast.

Why I write:

Let the words take me deeper,

like strings in the labyrinth,

becoming memories of how the world is

and really wants to be

I write

to cherish the living world

to keep my love flourishing

to call forth love, and to be called into the depths

Quick work

Topical, energetic, needs to be done sooner rather than later

Short work

Saying familiar things in new ways to different people 
Patchy work

Stitching up the pieces of my life, ideas and meanings resonating across mind and memory

Slow work

Finding me and capturing me from the inside, breaking my heart and calling me into words.

Beneath it all is the betrayal

I write in between betrayal and recovery, between fast action and slow heartbreak, between quick outreach and deep experience. And always the love comes greenly upspringing, bearing into sunlight and deep skies my desire to hold it together.

I write so that we of the living, even we who are lost and alone, can be called again into remembrance.

\section{Into fidelity}

There is a greater challenge here than might first be apparent. One of my favourite philosophers, Lev Shestov, says that for us moderns, faith is audacity: it is a refusal to regard everything as knowable. Shestov argues vigorously against the great "crime of modernity' which is to banish our capacity to encounter the unknown without subjecting it to human justification. One can read Shestov's audacity as a theological claim, which is certainly part of his project, but one can also read it today as an ecological claim. From this point of view, as long as the living world is fully alive it will be self-organising and self-repairing, and thus it is a dynamic system in which the whole will always exceed human understanding. It is not knowable as a whole by any of its constituent parts. Shestov's view is that the desire to be able to encompass and explain everything constitutes a forfeiture of 'the capacity to come into contact with the mysterious'.

Fidelity in both social and ecological terms is audacious because requires submission rather than mastery. It asserts that that which is here on earth not only exceeds human understanding but is pervasively mysterious. The term 'mysterious' provocatively acknowledges that an understanding of life on earth in its emerging fullness can never be totalised. This point is well known to many scientists and philosophers, and was stated quite delightfully be the ecologist Frank Egler: 'ecosystems may not only be more complex than we think, they may be more complex than we can think'. The audacity of fidelity becomes ever more challenging as we start to perceive the implications of life and death in the Anthropocene. It is clear that looming catastrophes are way beyond anything we can imagine or comprehend. The thought of all this unknowability can be paralysing. Fidelity is becoming increasingly difficult to discern. And still, and still, we are called into all this impossibility.

Egler was not arguing, and nor do I argue, that humility should become a cloak for ignorance. Far more interestingly, an acknowledgement of ultimate unknowability draws attention to how we punctuate and frame our questions. Toward which kinds of 
connections do we direct our research, and how may we throw our research and writing into connectivities that specifically work across and against fragmentation?

The beauty and greatness of life on earth is not a problem to be studied and resolved, but actually entails a particular kind of ethics - an obligation to keep faith with life by participating in and contributing to its immensity. Fidelity to that which cannot be fully known is absolutely integral to slow ethics, for this reason in particular: there is a temptation toward sorcery in catastrophe thinking. If, as is surely the case, that which is happening on earth is both catastrophic and beyond anything we can imagine, the temptation is to imagine that catastrophe impacts upon a living world that we can imagine. That is, the temptation is to contrast looming catastrophe with present knowledge, and to think that we know the world as it is, even if we do not know the world as it will become. This is a fundamental error, reproducing within the context of the Anthropocene the flawed certainties that have contributed to the cascading disasters. Audacious faith requires the humility of accepting that neither the world as it now is, nor the world as it is becoming, is fully knowable, and thus that we sustain our faith and our witness always in the face of our need to take ethical stands from within life processes that both radically precede and exceed us. Kate Rigby (2009: 69) urges us toward writing in the mode of 'prophetic witness', a practice that articulates from a slightly different perspective the audacious and humble faith I am advocating.

Writing with audacious faith is a practice that is not meant to unify anything. My 'Why I write' is an eruption, and I share it in the hopes that others, too, will continue to think again and again about how to sustain this work: how to keep the antidotes active, and how to put them in the service of the living world that sustains us. I imagine our work developing antidotes and fidelities undreamed of by auditors and other quality control experts. I long for fidelities that put forth entangled fronds, buds and flowers not yet imagined: fidelities that will contribute to trees yet to come, across whose leafy limbs we too may scamper.

\section{Acknowledgements}

Grateful thanks to Kangaloon, and to all the other people and institutions who have helped enable this research and writing. A very early version of this paper was presented as a plenary speech to the Annual Conference of the Cultural Studies Association of Australasia, Byron Bay, NSW, 7-9 December 2010, 'A Scholarly Affair'. Presentation title: 'Slow Scholarship'. My research into cultures and ethics of the Anthropocene, including extinction, is funded by an Australia Research Council grant (DP110102886).

\section{Works cited}

Andrews, Dan and Andrew Leigh 2009 'More inequality, less social mobility' Applied economic letters $16,1498-92$

Andrews, Geoff 2008 The slow food story: politics and pleasure, London: Pluto P

Apffel-Marglin, Frederique 1996 'Rationality, the body and the world: from production to regeneration', in Frederique Apffel-Marglin and Stephen Marglin (eds) Decolonising knowledge: from development to dialogue, Oxford: Oxford UP, 142-82 
Barad, Karen 2003 'Posthumanist performativity: toward an understanding of how matter comes to matter’ Signs 28: 3, 801-31

Bateson, Gregory 1979 Mind and nature: a necessary unity, Glasglow: Fontana/Collins

Bauman, Zygmunt 2004 Wasted lives: modernity and its outcasts, Oxford: Polity P

Beck, Ulrich, Anthony Giddens and Scott Lash 1994 Reflexive modernisation: politics, tradition and aesthetics in the modern social order, Stanford: Stanford UP

Bekoff, Marc and Pierce, Jessica 2009 Wild justice: the moral lives of animals, Chicago: U of Chicago $\mathrm{P}$

Boyle, Peter 2012 untitled, unpublished ms, 3/2/12

Cameron, Jenny and Rhyall Gordon 2010 'Building sustainable and ethical food futures through economic diversity: Options for a mid-sized city’. Paper presented at Policy workshop on the future of Australia's mid-sized cities. Bendigo, Victoria: Latrobe University, 28-9 September

Dietrich, William 1992 The final forest: the battle for the last great trees of the Pacific Northwest, New York: Penguin

Fackenheim, Emil 1994 To mend the world: foundations for post-holocaust Jewish thought, Bloomington: Indiana UP

Felman, Shoashana and Dori Laub 1992 Testimony: crises of witnessing literature, psychoanalysis and history, New York: Routledge

Friend, Bill 2004 'Deferral of the author: Impossible witness and Yasusada poems' Poetics today 25: 1, $137-58$

Haraway, Donna 1997 Modest_Witness@Second_Millenium.FemaleMan@ Meets_OncoMouse ${ }^{\mathrm{TM}}$. feminism and technoscience, New York: Routledge

Harvey, Graham 2006 Animism: respecting the living world, New York: Routledge

Hatley, James 2000 Suffering witness: the quandary of responsibility after irreparable, Albany: State U of New York P

Hogan, Linda 2010 Personal communication, 18 December

Hornborg, Alf 1994 'Environmentalism, ethnicity and sacred places: reflections on modernity, discourse and power' Canadian review of social and cultural anthropology 31: 3, 245-67

Judt, Tony 2010 Ill fares the land, New York: Penguin

Kaplan, Harold 2000 'The metapolitics of power and conflict', in Fredrick De Coste and Bernard Schwartz (eds) The Holocaust's ghost: writing art, politics, law and education, Edmonton: U of Alberta P, 65-74

Leopold, Aldo 1949 A sand county almanac, London: Oxford UP

Mazis, Glenn 2006 'Facing Levinas: Merleau-Ponty's physiognomic ethics' in James Hatley, Janice Mclane and Christine Diehm (eds) interrogating ethics: embodying the good in Merleau-Ponty, Pittsburgh: Duquesne UP, 185-205

Neithammer, Lutz 1992 Posthistoire: has history come to an end?, London: Verso

Oliver, Kelly 2001 Witnessing: beyond recognition, Minneapolis: U of Minnesota P

Plumwod, Val 2002 Environmental culture: the ecological crisis of reason, London: Routledge Plumwood, Val 2009 'Nature in the active voice' Australian humanities review 46 (May), 113-29

Pussey, Michael 1996 'Economic rationalism and the contest for civil society' Thesis eleven 44, 69-86

Rigby, Kate 2009 'Writing in the Anthropocene: idle chatter or ecoprophetic witness? Australian humanities review 47 (November), 69-86 
Rose, Deborah 2007 'Recursive epistemologies and an ethics of attention' in Jean-Guy Goulet and Bruce Miller (eds) Extraordinary anthropology: transformations in the Field, Lincoln: U of Nebraska P, 88-102

Rose, Deborah 2011 Wild dog dreaming: love and Extinction, Charlottesville: U of Virginia P

Roth, John 1999 'Introduction' in John Roth (ed) Ethics after the Holocaust: perspective, critiques and responses, St Paul: Paragon House, 1-15

Rowlands, Mark 2012 'The kindness of beasts' Aeon magazine, at http://www.aeonmagazine.com/being-human/mark-rowlands-animal-morality (accessed 30-10-12)

Ryan, Suzanna 2012 'Academic zombies: a failure resistance or a means of survival?' Australian universities review 54: 2, 3-11

Shestov, Lev 1970 'Children and stepchildren of time: Spinoza in history', in Bernard Martin (ed) $A$ Shestove anthology, Athens: Ohio UP, 215-43

Shestov, Lev 1970 Speculation and revelation, New York: Simon and Schuster

Stengers, Isabelle 2002 'Beyond conversation: the risks of peace', in Catherine Keller and Anne Daniel (eds) Process and difference: between cosmological and poststructuralist postmodernisms, Albany: SUNY, 235-55

Stengers, Isabelle 2008 'History through the middle: between macro and mesopolitics' Inflexions: $a$ journal for research-creation, 3 , at

http://www.senselab.ca/inflexions/volume_3/node_i3/stengers_en_inflexions_vol03.html (accessed 26 June 2010)

Thatcher, Margaret 1987 'AIDS, education and the year 2000!', Women's own, at http://www.margaretthatcher.org/document/106689 (accessed 13 November 2012)

Van Dooren, Thom 2011 'Vulture and their people in India: equity and entanglement in a time of extinctions' Australian humanities review 50, 45-61

Waldenfels, Bernhard 2002 'Levinas and the face of the other', in Simon Critchey and Robert Bernasconi (eds) The Cambridge companion to Levinas, Cambridge: Cambridge UP, 63-81 